\title{
Utilização dos princípios da manufatura enxuta e ferramenta de mapeamento de fluxo de valor para a identificação de desperdícios no estoque de produto acabado
}

\section{Utilization of the Lean manufacturing principles and value stream mapping for identification of waste in the finished product stock}

\author{
Ezequiel Heinen Sehnem \\ Liane Mahlmann Kipper ${ }^{2}$ \\ Juliana Ipê da Silva ${ }^{3}$ \\ Fábio de Freitas \\ Gustavo Trindade Choaire ${ }^{5}$
}

${ }^{1}$ Universidade de Santa Cruz do Sul Graduado em Engenharia de Produção pela Universidade de Santa Cruz do Sul, Rio Grande do Sul, Brasil. Supervisor de Produção.

zequisehnem@yahoo.com.br

2Universidade de Santa Cruz do Sul Doutora, professora no Programa de Pós Graduação em Sistemas e Processos Industriais, UNISC. Universidade de Santa Cruz do Sul, Rio Grande do Sul, Brasil. liane@unisc.br

${ }^{3}$ Universidade de Santa Cruz do Sul Graduada em Engenharia Química pela Universidade de Santa Cruz do Sul, Rio Grande do Sul, Brasil. juliana_ipe@hotmail.com

${ }^{4}$ Universidade de Santa Cruz do Sul Distribution Center Supervisor. Processing \& Logistic Department. Santa Cruz do Sul, Rio Grande do Sul, Brasil. fa.freita@yahoo.com.br

5Universidade de Santa Cruz do Sul Graduado em Engenharia Mecânica pela Universidade de Santa Cruz do Sul, Rio Grande do Sul, Brasil. gtchoaire@mx2.unisc.br

\begin{abstract}
Resumo
Por muito tempo os princípios e ferramentas da manufatura Lean foram utilizadas somente em linhas de produção, mas com a otimização desse sistema produtivo constatou-se que os benefícios do Mapeamento de Fluxo de Valor (MFV) poderiam ser aplicados em toda a organização. Assim, o objetivo deste artigo foi realizar o MFV no processo de estocagem de produto acabado de uma empresa do setor tabagista. Para isto a metodologia utilizada foi um estudo de caso em uma empresa de grande porte com o intuito de mapear o fluxo de valor do processo de estocagem de produto acabado. A partir do Mapeamento do Fluxo de Valor, foram identificadas oportunidades de melhorias como a avaliação da real necessidade do Cooling e da separação de volumes por container. A parir dos estudos realizados e representados no MFV com símbolo do Kaizen, a criação de uma planilha automática para agilizar o procedimento de embarque foi proposta, assim como o estado futuro com as proposições de melhoria para o processo.
\end{abstract}

Palavras-chave: Manufatura Enxuta. Gestão de Estoque. Mapa de Fluxo de Valor. Desperdícios.

Abstract

For a long time Lean manufacturing principles and tools were used only in production lines, but with the optimization of this production system it was found that the benefits of Value Stream Mapping (VSM) could be applied throughout the organization. Thus, the objective of this article was to perform the VSM in the process of stocking the finished product of a tobacco company. For this the methodology used was a case study in a large company with the intent of mapping the flow of finished product storage process value. From the Value Stream Mapping, opportunities for improvements such as the evaluation of the real need for Cooling and the separation of volumes per container were identified. Based on the studies performed and represented in the VSM with the Kaizen symbol, the creation of an automatic spreadsheet to expedite the boarding procedure was proposed, as well as the future state with the improvement proposals for the process.

Keywords: Lean Manufacturing. Inventory Management. Value Stream Mapping. Waste Reduction. 


\section{Introdução}

Para se estabelecer no atual mercado competitivo, as empresas estão buscando formas inovadoras para reorientarem a pesquisa e o desenvolvimento de métodos que visam a melhoria dos processos produtivos (Vinodh \& Joy, 2012). A competitividade faz com que as organizações reestruturem suas estratégias de gerenciamento para reduzir a complexidade a fim de se manterem competitivos no mercado (Li, Tao, Cheng, Zhang \& Nee, 2017). Segundo Tayyab \& Sarkar (2016) as aplicações e utilizações das técnicas de manufatura enxuta estão ligadas diretamente à alta competitividade no mercado global e cada vez mais elas estão sendo incorporadas pelos sistemas de produção (Tortorella, Miorando \& Marodin, 2017). O objetivo deve ser de compreender e organizar da melhor maneira todas as etapas do processo produtivo, obtendo maior produtividade, um nível adequado de estoque e eliminando os desperdícios (Pinto, Tortato, Veiga \& Catapan, 2013), sem deixar de atender as necessidades dos clientes.

Atualmente o sistema de produção que visa a redução de custo por meio da eliminação total das perdas é o Sistema Toyota de Produção (STP), como firmemente comenta Shingo (1996) que a quantidade produzida deve ser igual à quantidade demandada, eliminando a superprodução por meio da noção de não estoque e atendendo a demanda com uma produção puxada.

A gestão de estoques é fundamental para o sucesso da prática enxuta, segundo Zylstra (2008) a reposição puxada precisa de estoque para atender os leads times do serviço ao cliente e é o pulmão necessário para se proteger das variações. Um nível de serviço deve ser calculado para a reposição puxada dar conta de atender os clientes, ou seja, um estoque enxuto, mas suficiente. Se houver muito estoque, irá fugir do conceito enxuto gerando desperdício, se houver pouquíssimo estoque, podem ocorrer faltas ou apressamento excessivo para atender as demandas dos clientes. Pinto, Tortato, Veiga \& Catapan (2013) descrevem a gestão de estoque como sendo uma estratégia muito valiosa para as organizações devido a aquisição de competitividade por meio de recessão de desperdício. A gestão de estoques busca o equilíbrio adequado para que a reposição puxada seja eficaz e permita a eliminação contínua das perdas (Wu \& Low, 2014).

No ponto de vista empresarial, uma das ferramentas lean que mais trazem resultados financeiros significativos é o MFV, pois ele facilita a aplicação dos princípios enxutos quando documenta todo o processo. Com o MFV pode-se obter uma maior clareza dos processos e identificar possíveis desperdícios (Dal Forno et al., 2014; Lima \& Loss, 2017), pois além de ajudar a visualizar os processos individuais, é possível enxergar o fluxo de valor, ajudado a identificar as fontes de desperdício, formando a base de referência para um plano de implementação enxuta (Lima, 2007).

Este artigo limita-se a realizar um estudo de caso em uma empresa do setor do tabagista e mapear o fluxo de valor do processo de estocagem de produto acabado desta empresa, desde o recebimento até 
embarque e o monitoramento para melhor clareza dos processos e identificação de possíveis gargalos, por meio de técnicas da manufatura lean, propor soluções para minimização de desperdícios e obter uma melhor eficiência na operação.

\section{Referencial teórico}

Conforme Shingo (1996) e reforçado por Antunes et al. (2008) a perda é qualquer atividade que gera custo e não agrega valor ao produto, como movimentações desnecessárias, transporte, espera e retrabalho. As atividades que agregam valor ao produto são as atividades que realmente transformam a matéria-prima de acordo com as necessidades dos clientes. A produção enxuta identifica sete tipos de perdas, são elas: superprodução, espera, transporte, processamento, estoque, movimentação, fabricação de produtos defeituosos.

Saurin, Ribeiro \& Marodin (2010) realizaram um levantamento do processo de implantação da Produção Enxuta (PE) em 47 empresas do Brasil e do exterior. Os temas de maior interesse apresentados pelos resultados desta pesquisa foram: a ampliação de conhecimentos sobre a cultura organizacional enxuta e o mapeamento do fluxo de valor. Sobre os principais motivos dos empresários em adotar a PE estão a necessidade de melhorar a competitividade e a adequação da PE ao combate de problemas críticos da produção (Saurin, Ribeiro \& Marodin, 2010). Observa-se que o mapeamento de fluxo de valor tem norteado projetos de transformação, pois permite às empresas enxergar seus desperdícios, auxiliando para direcionar as melhorias no fluxo e contribuir para um salto no desempenho (Rother \& Shook, 2003). Na gestão de estoques isto não é diferente. Assim a fundamentação teórica aborda a gestão de estoques e a distribuição Lean, tratando dos desperdícios e dos caminhos para a proposição de melhorias.

Borges et al., (2010) postula que a distribuição enxuta pode contribuir com o objetivo da logística, aumentando os níveis de serviços e diminuindo os custos totais (Swenseth \& Olson, 2016). A aplicação desta metodologia pode impactar diretamente na estabilidade, flexibilidade, capacidade de reação e confiabilidade do sistema logístico, caracterizando uma vantagem competitiva sobre os concorrentes seja qual for o segmento de atuação.

Zylstra (2008) diz que os princípios da Produção Enxuta estão mudando as características da saída da produção da fábrica para a distribuição. Enquanto a prática enxuta tem influenciado as operações de produção, os tamanhos dos lotes de produção, qualidade e flexibilidade estão sendo otimizados. Quanto mais a prática enxuta tem influenciado, mais os estoques têm reduzido, mais a programação é simplificada e a qualidade é melhorada. 
O MFV ou Value Stream Map (VSM) é uma ferramenta essencial do Lean que utiliza símbolos, métricas e setas (Venkataraman, Ramnath, Kumar \& Elanchezhian, 2014), para mostrar e aprimorar a identificação no processo de todas as etapas do processamento do produto (Machado, 2014; Machado et al., 2015).

Rother e Shook (2003) definem fluxo de valor como toda ação necessária para trazer um produto, ou seja, todos os fluxos (processos) essenciais que cada produto passa, além de ser uma valiosa ferramenta que permite a identificação dos desperdícios de qualquer processo (Lee, Grooms Mamidala \& Nagy, 2014) que ocorrem durante toda a cadeia do processo (Paredes \& Godinho Filho, 2017). O MFV auxilia na projeção de um "estado futuro" de como a produção teria que fluir, a partir da melhoria do "estado atual" de um processo por meio dos princípios do pensamento enxuto.

O MFV do estado atual de um processo é uma ferramenta que deve ser visualizada da direita para a esquerda, ou seja, do cliente (Distribuição) ao fornecedor, para garantir que o fluxo seja executado em benefício da produção sem perdas e focado no valor para o cliente.

O MFV do estado futuro de um processo possui os cartões kanban que indicam a requisição de mais material ao estágio fornecedor (Cottyn, Van Landeghem, Stockman \& Derammelaere, 2011) e as necessidades de kaizen que evidenciam as melhorias primordiais em processos específicos que são de extrema importância para atingir o fluxo de valor desejado (Modarress, Ansari \& Lockwood, 2005).

Conforme Rother e Shock (2003) e Machado (2014), para montar o MFV, o primeiro passo é a seleção de uma família de produtos, em seguida seguir a trilha de produção de porta a porta na planta, do consumidor ao fornecedor, para desenhar, atenciosamente, o mapa de estado atual com os fluxos de material e de informação. Seguidamente, elaborar o MFV do estado futuro do jeito que o valor deveria fluir, melhorando o fluxo de material e de informação e analisando a minimização dos desperdícios, gerando valor para o cliente.

Shingo (1996) postula que o lead time apresenta o tempo de execução completo do processo, desde o recebimento da matéria-prima até o envio do produto acabado, mostrando a flexibilidade do processo em atender as demandas de seus clientes, e considera que quanto menor for o tempo de execução do processo, menor será o custo de produção.

Segundo Carillo (2000), separar o lead time "Em Estoque" dos outros leads times é uma maneira útil para avaliação, pois ilustra o efeito cumulativo do estoque e seu relacionamento com o processo logístico, conforme o exemplo a seguir. 
Figura 1 - Lead time acumulado

(Em Dias)

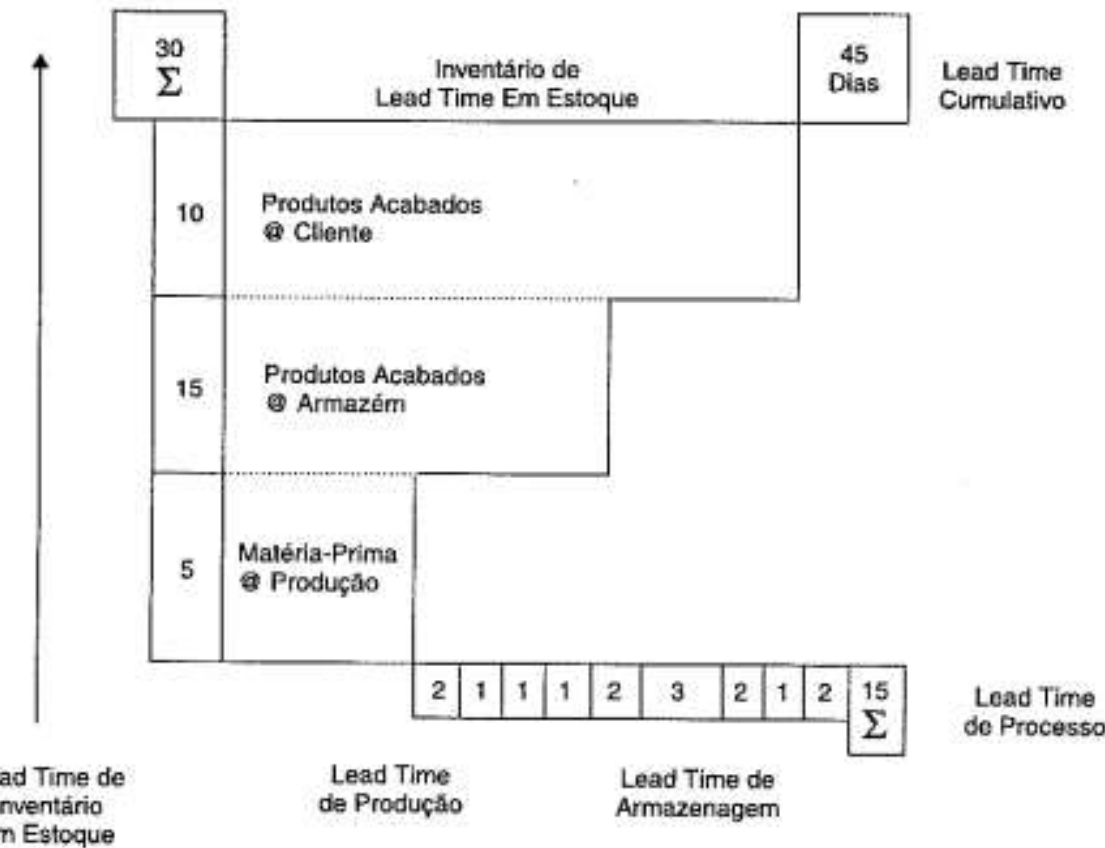

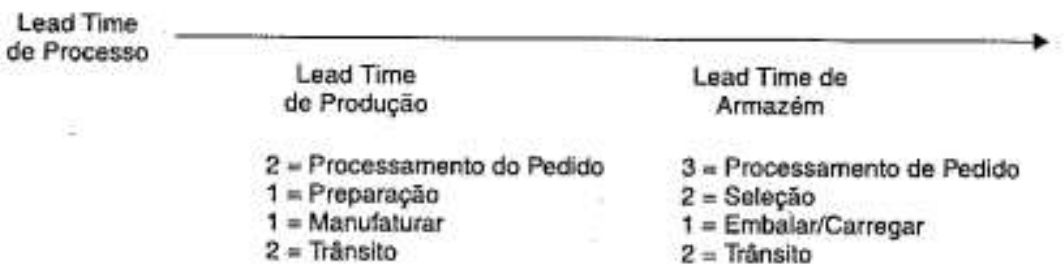

Fonte: Carillo, 1997, p.32.

A figura 1 ilustra o acúmulo de lead time em estoque desde o fabricante até os produtos entregues ao cliente, sem apresentar os leads times de Compras e Pagamento. Pode-se observar que são mantidos 5 dias de estoque de matéria prima, o processo de produção leva 5 dias mais 2 dias em trânsito ao armazém, onde produtos acabados são mantidos por 15 dias. O processamento do armazém leva 6 dias mais 2 dias em trânsito ao cliente, que mantém 10 dias de estoque de produtos acabados.

Carillo (2000) explica que, neste exemplo o inventário em estoque de 30 dias é encontrado com um lead time de processo de 15 dias, ou seja, o inventário não está sendo movimentado e é de alto custo agregado. O processamento envolve movimentação e está adicionando valor por meio das mudanças de lugar e das mudanças à forma do produto. Essa análise indica claramente as áreas críticas da formação do lead time, facilitando uma avaliação adequada e as ações a serem tomadas. 
Segundo Rother e Shook (2003), takt time é a frequência que determinado produto deve ser produzido, baseado no ritmo das vendas para suprir a demanda dos clientes. O takt time é calculado conforme a equação 1:

\section{Takt Time $=\underline{\text { tempo de trabalho disponível por turno }}$ demanda do cliente por turno}

O takt time é utilizado para sincronizar os processos, sendo uma referência que dá noção do ritmo que cada processo deveria estar sendo produzido e auxilia a enxergar o que precisa ser feito para melhorar (Rother \& Shook, 2003).

Conforme Rother e Shook (2003), o mapeamento de fluxo de valor ajuda a enxergar e entender o fluxo de material e de informação enquanto o produto segue o fluxo de valor, tornando os processos mais claros, ficando mais fácil de enxergar o valor e as fontes de desperdício, auxiliando a gestão a tomar decisões para obter melhor eficiência na operação, reduzindo custos.

Com o MFV fica mais fácil identificar possíveis desperdícios, pois além de ajudar a visualizar os processos individuais, é possível enxergar o fluxo de valor, ajudado a identificar as fontes de desperdício, formando a base de referência para um plano de implementação enxuta (Lima, 2007).

Em todo o processo produtivo há fluxo de materiais e fluxo de informação. Logo os ícones para realizar o mapeamento do fluxo de valor do estado atual e do estado futuro são divididos em três categorias: ícones que indicam o fluxo de materiais, ícones que indicam o fluxo de informações e ícones gerais (Rother e Shook, 2003).

Os símbolos são utilizados para construção do MFV do estado atual, identificação das melhorias, e MFV do estado futuro, permitindo a visualização do processo de maneira simplificada, informando o fluxo de materiais, informações, processos, clientes, fornecedores, dados e operadores do produto estudado.

Além do MFV outras ferramentas e técnicas são propostas pelo sistema enxuto de produção. A ferramenta denominada Just in Time e o sistema kanban (Marafon de Paoli, Cezar \& da Silva Santos, 2016) são duas das principais ferramentas aplicadas à manufatura enxuta e o kaizen é um termo muito utilizado que indica a melhoria contínua (Becker Mendes de Oliveira, Alves Corrêa, \& Nicolini do Patrocínio Nunes, 2013), aparecendo sempre que trata da manufatura enxuta, também conhecida como Sistema Toyota de Produção.

\section{Metodologia}

A partir do objetivo estabelecido neste artigo que é de: realizar o Mapeamento de Fluxo de Valor no processo de estocagem de produto acabado de uma empresa do ramo tabagista para melhor clareza dos processos identificando desperdícios, para proposição de possíveis oportunidades de melhoria; 
entende-se que o método estudo de caso atende o objetivo estabelecido. Segundo Yin (2005), o método conhecido como estudo de caso contribui de forma especial para a compreensão dos fenômenos individuais, organizacionais, sociais e políticos. Assim, para melhor entendimento do processo organizacional de estocagem de produto acabado, foram realizadas as quatro etapas do estudo de caso propostas por Gil (2017), quais sejam: definição da unidade-caso; coleta de dados; seleção, análise e interpretação dos dados; e elaboração do relatório, ou seja, apresentação e análise dos resultados.

Para a definição da unidade-caso foi marcada uma reunião com a gestão da área de logística. A unidadecaso escolhida foi o processo de estocagem de produto acabado por necessitar de um olhar mais aprofundado do processo. Foi realizado uma visita ao processo (sondagem inicial), juntamente com os responsáveis da unidade-caso, para conhecimento de cada etapa que compõe a unidade escolhida.

Posteriormente, foi realizada a coleta de dados teóricos e empíricos. Os dados teóricos foram coletados por meio de revisão da literatura para embasamento do trabalho. Posteriormente, foi realizada a coleta de dados da empresa para elaboração do MFV, durante um período de três meses de acompanhamento dos processos, utilizando as seguintes técnicas:

- Diálogos com o gestor da área de logística e pessoas chave que participam da equipe de gerenciamento de estoques para coleta de dados da situação atual da gestão de estoques, tamanho de lote, como é definido e controlado, como operam os processos de estocagem e as principais perdas percebidas pelo gestor e sua equipe como o tempo de preparação para embarque e o recebimento das caixas com mistura de lotes.

- Observação em loco do fluxo de informações e materiais em cada etapa do processo de estocagem de produto acabado, acompanhando minuciosamente cada passo das equipes de trabalho, coletando os dados e esclarecendo as atividades com a equipe operacional para construir o MFV do estado atual.

- Cronometragem foi realizada para registrar os tempos de realização das atividades existentes em cada etapa do processo. Os tempos das atividades foram cronometrados e anotados em uma folha de registro, juntamente com a descrição das atividades e observações. Cada atividade foi cronometrada no mínimo 4 vezes, em dias e horários alternados, para ser feito uma média de cada tempo, a fim de definir o tempo médio por atividade. Algumas atividades como o Embarque não são realizadas todos os dias, por isso outras atividades foram cronometradas mais vezes, sendo feito o possível conforme o dia de acompanhamento. 
Apresentação e análise dos resultados

A construção do MFV do estado atual foi realizada primeiramente em papel, seguindo a ordem descrita dos processos realizados na estocagem de produto acabado e após foi desenhado a mão em um grande quadro para facilitar o entendimento e exposição das ideias, definindo os seis principais processos que são:

- Recebimento;

- Cooling;

- Preparação para Embarque;

- Expurgo;

- Embarque.

Pode-se observar na figura 2 o quadro do MFV.

Figura 2 - MFV do estado atual desenhado a mão

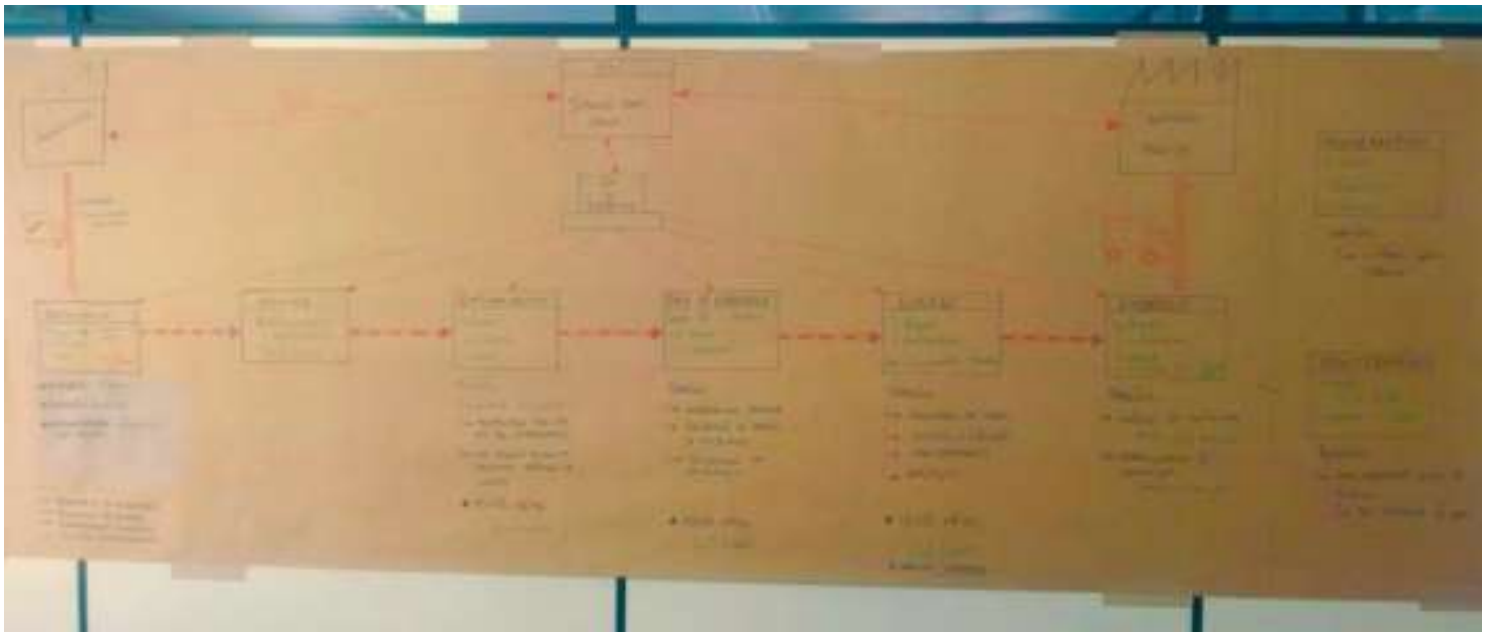

Fonte: Autores, 2016.

Após a construção do MFV do estado atual desenhado a mão, o mesmo foi digitalizado e complementado com o auxílio do software Microsoft Visio, apresentado no apêndice A.

Com os dados obtidos e o MFV do estado atual em mãos, foi calculado o takt time e o lead time acumulado em estoque, como pode-se ver a seguir.

\subsection{Cálculo do Takt Time}


Na Unidade de Produto Acabado (PA) o tempo de trabalho disponível por turno é de 8 horas, ou seja, 28.800 segundos. Devido à safra do fumo, o PA trabalha em torno de 5 meses por ano com dois turnos, e 7 meses com um turno.

A demanda do cliente por dia (para fim de cálculo) é de 25 containers em 2 turnos ( 2.475 caixas), sendo que 20 containers são embarcados no turno do dia. No turno da noite que começa às 22 horas não considera as 8 horas de embarque, pois só a partir das 3 da manhã começam a carregar os caminhões. Geralmente, na média são embarcados 20 containers por dia (1980 caixas), mas o recorde em um dia é 35 containers.

A partir desses dados, foi calculado o Takt time, conforme equação 1:

\author{
Takt Time $=\underline{\text { tempo de trabalho disponível por turno }}$ (1) \\ demanda do cliente por turno \\ Takt Time $=\underline{28.800 \text { segundos }}=14,54$ segundos $/$ caixa $(1)$ \\ 1.980 caixas
}

\title{
3.2. Lead Time acumulado
}

Seguindo as ideias de Carillo (2000) em separar o lead time "Em Estoque" dos outros leads times para facilitar a avaliação, foi criado o mapa de lead time dos processos na Unidade de Produto Acabado da empresa em estudo, conforme figura 3. 
Figura 3 - Lead time acumulado

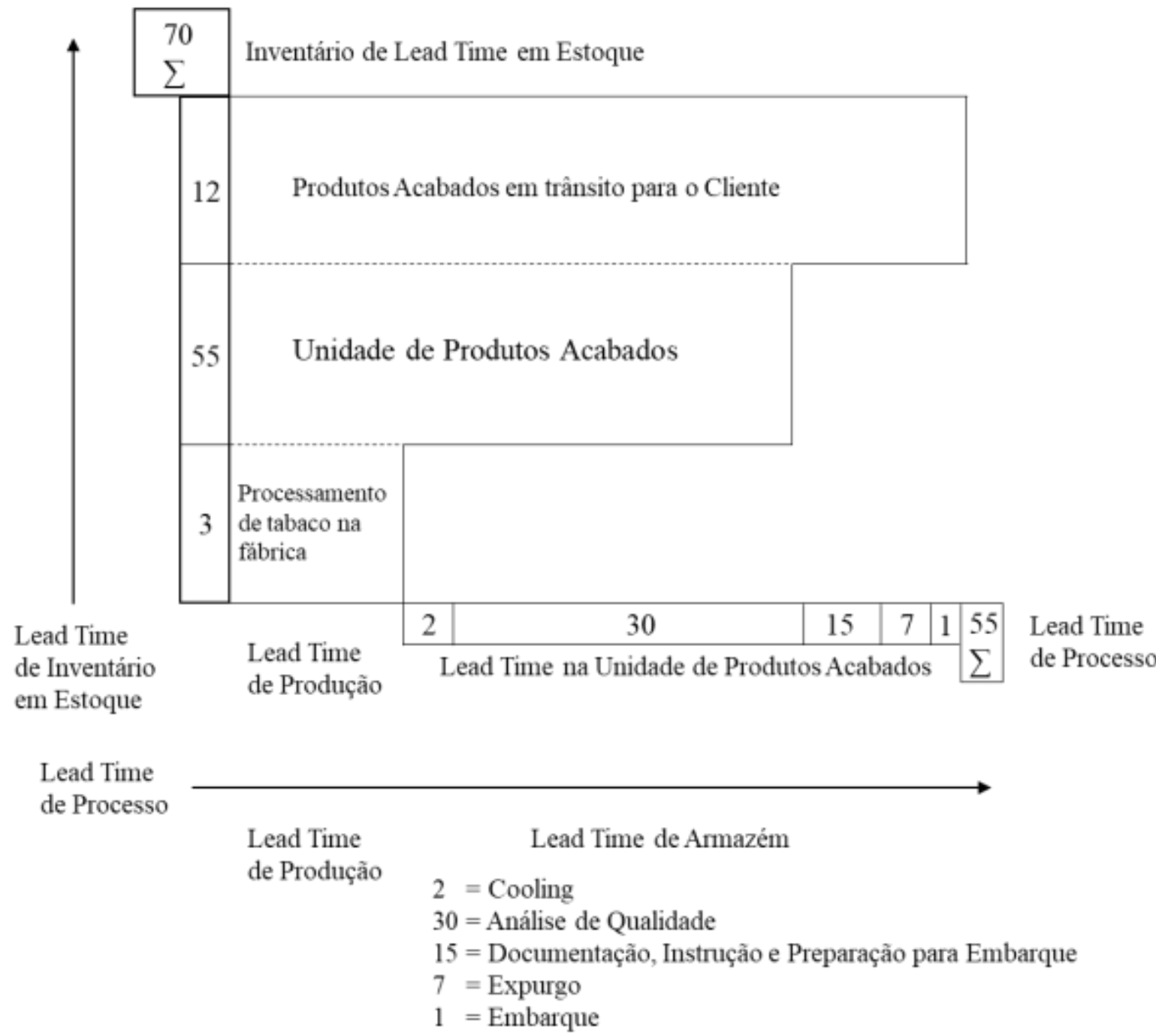

Fonte: Adaptado Carillo, 1997, p.32.

\section{Resultados}

Percebe-se na figura 3, que o produto acabado fica no estoque por 55 dias, mas o caso do tabaco é um caso atípico, pois o produto acabado passa por processos dentro da Unidade de estocagem para garantir a qualidade do produto e mantê-lo livre de parasitas. Mesmo assim, esse período é muito longo e precisa ser reduzido, pois, o inventário é de alto custo agregado. Essa análise indica claramente que as áreas críticas da formação do lead time são os 45 dias entre os 30 dias na análise de qualidade, mais 15 dias nas inspeções de origem de liberação de lote, composição do preço, instrução e preparação para embarque.

A partir da análise do Mapa de Fluxo de Valor Atual em conjunto com gestor da área onde o trabalho foi desenvolvido, foram identificadas as principais perdas que são: 
- Perdas por movimentação: principalmente porque as caixas chegam misturadas no PA pois algumas ficam na processadora para coletas das amostras de qualidade, depois são misturadas com outro lote, e para serem embarcadas precisam estar no lote e intervalo correto entre as 99 caixas, e para isso, é necessária uma equipe com empilhadeiras para desempilhar as caixas e empilhar novamente separando os volumes;

- Perdas por espera: principalmente na preparação para embarque, onde as caixas ficam aguardando no PA por 45 dias, como pode-se ver no mapa do lead time e no MFV atual;

- Perdas por processamento: em processos que talvez não sejam realmente necessários, como o Cooling e a separação no intervalo das 99 caixas.

A partir da identificação das perdas, algumas oportunidades de melhorias foram propostas visando minimizar cada desperdício e foi elaborado um plano de ação que sugere as ações a serem tomadas. 0 plano de ação poderá auxiliar no acompanhamento das atividades para que se atinja o melhor resultado possível, como pode-se ver na tabela 1 a seguir. Diante da impossibilidade de acesso aos fornecedores e as empresas que portam contratos, os custos "a confirmar" ficaram impossibilitados de possuírem estimação de valores.

Tabela 1 - Plano de Ação com Oportunidades de Melhorias

\begin{tabular}{|l|l|l|l|l|l|l|}
\hline \multicolumn{1}{|c|}{ O quê? } & \multicolumn{1}{|c|}{ Por quê? } & \multicolumn{1}{c|}{ Quem? } & Quando? & \multicolumn{1}{c|}{ Onde? } & \multicolumn{1}{c|}{$\begin{array}{l}\text { Quanto } \\
\text { custa? }\end{array}$} \\
\hline $\begin{array}{l}\text { Receber as caixas no } \\
\text { PA sem mistura }\end{array}$ & $\begin{array}{l}\text { Para reduzir os } \\
\text { tempos do } \\
\text { empilhamento }\end{array}$ & $\begin{array}{l}\text { Equipe da } \\
\text { processadora }\end{array}$ & dez/16 & Processadora & $\begin{array}{l}\text { Treinar equipe da } \\
\text { processadora e } \\
\text { organizar o envio das } \\
\text { caixas p/ PA }\end{array}$ & Zero \\
\hline $\begin{array}{l}\text { Reduzir o tempo de } \\
\text { movimentação e } \\
\text { endereçamento }\end{array}$ & $\begin{array}{l}\text { Para agilizar o } \\
\text { processo de } \\
\text { Recebimento }\end{array}$ & $\begin{array}{l}\text { Equipe do } \\
\text { PA }\end{array}$ & dez/16 & Recebimento & $\begin{array}{l}\text { Wi-Fi e alocar as } \\
\text { caixas em locais } \\
\text { próximos }\end{array}$ & A confirmar \\
\hline $\begin{array}{l}\text { Avaliar a real } \\
\text { necessidade do } \\
\text { Cooling }\end{array}$ & $\begin{array}{l}\text { Para poder } \\
\text { retirar esse } \\
\text { processo se for } \\
\text { possível }\end{array}$ & $\begin{array}{l}\text { Supervisão e } \\
\text { Gerência }\end{array}$ & dez/16 & Cooling & $\begin{array}{l}\text { Fazer testes da } \\
\text { temperatura interna das } \\
\text { caixas }\end{array}$ & Zero \\
\hline $\begin{array}{l}\text { Avaliar a } \\
\text { necessidade de } \\
\text { separar no intervalo } \\
\text { das } 99 \text { caixas }\end{array}$ & $\begin{array}{l}\text { Para reduzir os } \\
\text { tempos de } \\
\text { empilhamento } \\
\text { e prep. p/ } \\
\text { embarque }\end{array}$ & $\begin{array}{l}\text { Supervisão e } \\
\text { Gerência }\end{array}$ & dez/16 & $\begin{array}{l}\text { Empilhamento } \\
\text { e Preparação } \\
\text { p/ embarque }\end{array}$ & $\begin{array}{l}\text { Avaliar outras } \\
\text { Unidades e se possível, } \\
\text { separar apenas dentro } \\
\text { do intervalo dos lotes }\end{array}$ & Zero \\
\hline
\end{tabular}




\begin{tabular}{|c|c|c|c|c|c|c|}
\hline $\begin{array}{l}\text { Reduzir o tempo de } \\
\text { espera pela análise } \\
\text { de qualidade }\end{array}$ & $\begin{array}{l}\text { Para diminuir } \\
\text { o acúmulo de } \\
\text { produto } \\
\text { acabado neste } \\
\text { período }\end{array}$ & Gerência & mar/17 & $\begin{array}{l}\text { Preparação } \\
\text { para } \\
\text { embarque }\end{array}$ & $\begin{array}{l}\text { Identificar um } \\
\text { laboratório no Brasil } \\
\text { que faça o teste de } \\
\text { toxidade }\end{array}$ & A confirmar \\
\hline $\begin{array}{l}\text { Desburocratizar a } \\
\text { documentação de } \\
\text { liberação para o } \\
\text { embarque }\end{array}$ & $\begin{array}{l}\text { Para reduzir o } \\
\text { tempo de } \\
\text { espera pela } \\
\text { documentação }\end{array}$ & Gerência & mar/17 & $\begin{array}{l}\text { Preparação } \\
\text { para } \\
\text { embarque }\end{array}$ & $\begin{array}{l}\text { Avaliar quais são os } \\
\text { documentos que mais } \\
\text { demoram para estarem } \\
\text { prontos e simplificá-los }\end{array}$ & Zero \\
\hline $\begin{array}{l}\text { Criar planilhas } \\
\text { automáticas para } \\
\text { auxiliar a gerar o } \\
\text { Método de embarque }\end{array}$ & $\begin{array}{l}\text { Para reduzir o } \\
\text { tempo de } \\
\text { criação das } \\
\text { planilhas }\end{array}$ & Equipe de TI & $\mathrm{dez} / 16$ & $\begin{array}{l}\text { Preparação } \\
\text { para } \\
\text { embarque }\end{array}$ & $\begin{array}{l}\text { Entrar em contato com } \\
\text { a equipe de TI para } \\
\text { desenvolverem as } \\
\text { planilhas necessárias }\end{array}$ & Zero \\
\hline $\begin{array}{l}\text { Reduzir os tempos } \\
\text { de embarque }\end{array}$ & $\begin{array}{l}\text { Para agilizar o } \\
\text { processo de } \\
\text { Embarque }\end{array}$ & $\begin{array}{l}\text { Equipe do } \\
\text { PA }\end{array}$ & $\mathrm{dez} / 16$ & Embarque & $\begin{array}{l}\text { Limpar } 2 \text { caminhões ao } \\
\text { mesmo tempo, } \\
\text { revezando as equipes } \\
\text { nas atividades }\end{array}$ & Zero \\
\hline
\end{tabular}

Fonte: Autores, 2016.

Todas as oportunidades de melhorias descritas no Plano de Ação foram representadas no MFV do estado atual com símbolos da necessidade de Kaizen, como pode-se ver no apêndice B.

Na construção do MFV do estado futuro, representado no apêndice C, foi considerado que todas as melhorias propostas no Plano de Ação (tabela 1) estivessem implementadas, dando uma visão de como seria o estado "ideal" da Unidade de Produto Acabado da empresa em estudo. Atendendo apenas as melhorias das áreas críticas da formação do lead time, identificadas no mapa de lead time acumulado (figura 3), foi considerado que seria possível reduzir o tempo de análise de qualidade de 30 dias para 7 dias e o tempo das inspeções de origem, composição do preço, instrução e preparação para embarque de 15 dias para 3 dias, como pode ser observado na figura 4. 
Figura 4 - Lead time futuro

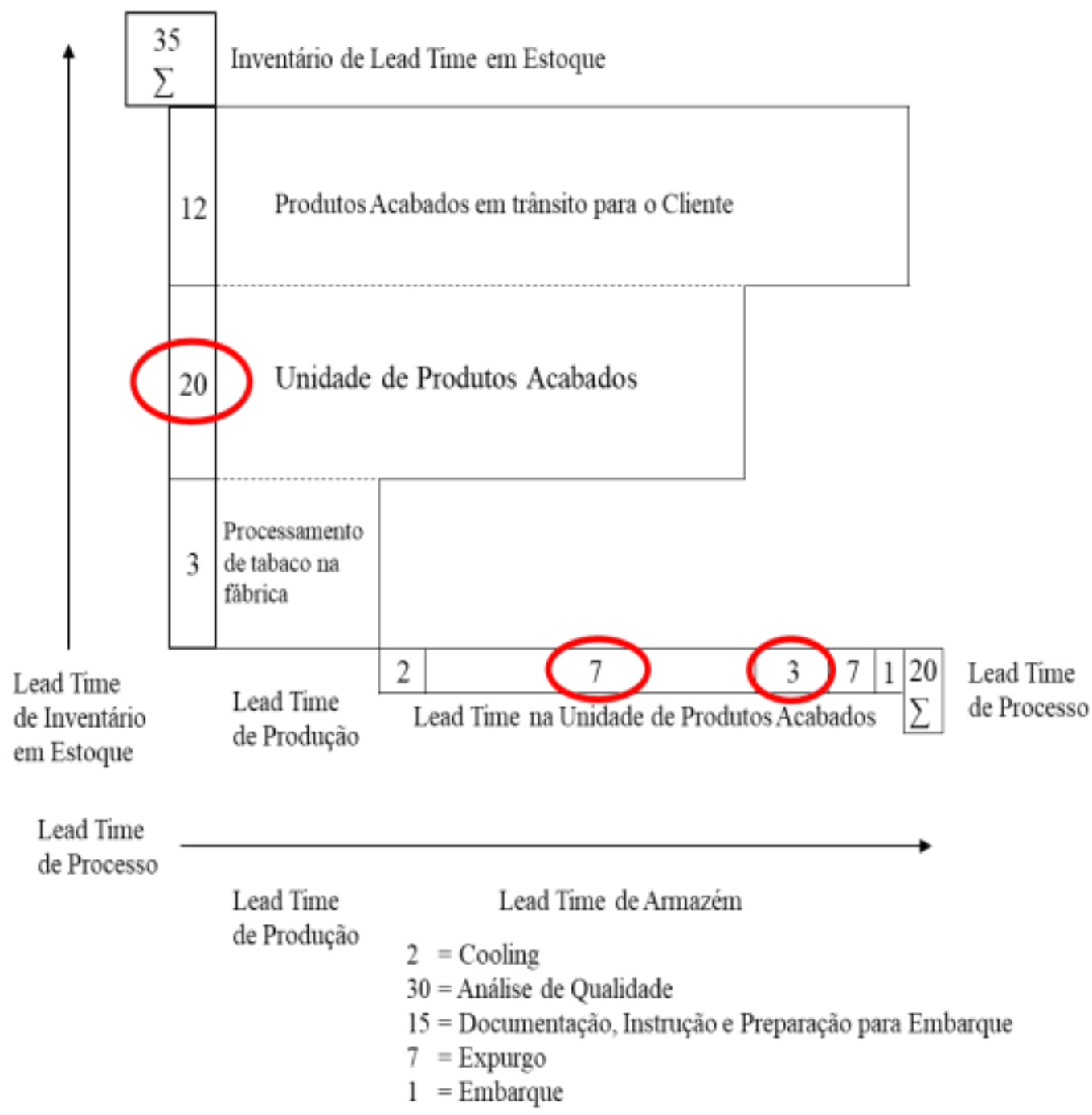

Fonte: Autores, 2016.

Pode-se observar que os produtos que eram mantidos no PA por no mínimo 55 dias, após identificar um laboratório no Brasil que faça o teste de toxidade e desburocratizar a documentação de liberação para o embarque, passaram a ser mantidos no PA por 20 dias, havendo uma redução do lead time em $63,6 \%$.

Percebe-se no apêndice $C$ que o estado futuro ficou mais simplificado, dando uma visão enxuta do processo, e reduzindo ainda mais o lead time, passando a ser de 17,16 dias, ou seja, uma redução total de $68,4 \%$, onde foram retirados processos que não eram necessários como o Cooling e simplificados outros processos. 


\section{Conclusão}

O objetivo do estudo foi realizar o Mapeamento de Fluxo de Valor no processo de estocagem de produto acabado de uma empresa do setor tabagista para melhor clareza dos processos, identificando desperdícios com foco na proposição de possíveis oportunidades de melhoria.

A partir da identificação das perdas, algumas oportunidades de melhorias foram propostas visando minimizar cada desperdício, como: avaliar a real necessidade do Cooling, avaliar a necessidade de separar no intervalo das 99 caixas, identificar um laboratório no Brasil que faça o teste de toxidade, desburocratizar a documentação de liberação para o embarque, e criar planilhas automáticas para auxiliar a gerar o método de embarque.

As oportunidades identificadas foram representadas no MFV do estado atual com símbolos da necessidade de Kaizen, como pode-se ver no apêndice B, e foi elaborado um plano de ação, conforme tabela 1, que sugere as ações a serem tomadas e poderá auxiliar no acompanhamento das atividades para que se atinja o melhor resultado possível.

Utilizando as lições do sistema Lean e a concretização das oportunidades de melhoria, foi construído o MFV do estado futuro, representado no apêndice $C$, considerando que todas as melhorias propostas estivessem implementadas, dando uma visão de como seria o estado "ideal" da Unidade de Produto Acabado. O estado futuro ficou mais simplificado, dando uma visão enxuta do processo, havendo uma redução do lead time em $68,4 \%$, auxiliando a empresa a desenvolver vantagens competitivas em seus sistemas logísticos.

Uma limitação do presente estudo ocorreu por ser um estudo de caso único com a realização do mapeamento o fluxo de valor do processo de estocagem de produto acabado. Assim, uma sugestão para trabalhos futuros está na realização de estudos semelhantes em empresas do mesmo setor ou de outros setores produtivos buscando comparar os resultados da aplicação do mapeado o fluxo de valor e seus resultados. Sugere-se também que ocorra a ampliação no tempo de coleta de dados, tendo em vista que há sazonalidade na produção que oscila conforme a demanda do cliente e safra do tabaco.

\section{Referências}

Antunes, J., Alvarez, R., Klippel, M., Bortolotto, P., \& PELLEGRIN, I. (2008). Sistemas de produção: sistemas e práticas para projeto e gestão da produção enxuta.

Becker Mendes de Oliveira, R., Alves Corrêa, V., \& Nicolini do Patrocínio Nunes, L. E. (2013). Uso da simulação computacional com o mapeamento do fluxo de valor para auxiliar na tomada de decisão. Exacta, 11(1). 
Camelo, G. R., Coelho, A. S., Borges, R. M., \& Souza, R. M. (2010). Logística enxuta: a abordagem Lean na cadeia de suprimentos. XXX Encontro Nacional de Engenharia de Produção.

Cottyn, J., Van Landeghem, H., Stockman, K., \& Derammelaere, S. (2011). A method to align a manufacturing execution system with Lean objectives. International Journal of Production Research, 49(14), 4397-4413.

Dal Forno, A. J., Pereira, F. A., Forcellini, F. A., \& Kipper, L. M. (2014). Value Stream Mapping: a study about the problems and challenges found in the literature from the past 15 years about application of Lean tools. The International Journal of Advanced Manufacturing Technology, 72(5-8), 779-790.

Carillo JR, E. (1997). Gerenciamento da Logística e Cadeia de Abastecimento. São Paulo: IMAM.

Carillo JR, E. (2000). Gerenciamento da Logística e Cadeia de Abastecimento. São Paulo: IMAM.

Gil, A. C. (2017). Como elaborar projetos de pesquisa. São Paulo: Atlas.

Lee, E., Grooms, R., Mamidala, S., \& Nagy, P. (2014). Six easy steps on how to create a lean sigma value stream map for a multidisciplinary clinical operation. Journal of the American College of Radiology, 11(12), 1144-1149.

Li, Y., Tao, F., Cheng, Y., Zhang, X., \& Nee, A. Y. C. (2017). Complex networks in advanced manufacturing systems. Journal of Manufacturing Systems, 43, 409-421.

Lima, A. D. C. (2007). Práticas do pensamento enxuto em ambientes administrativos: aplicação na divisão de suprimentos de um hospital público.

Lima, P. A. M., \& Loos, M. J. (2017). Aplicação de fluxo contínuo como contribuição no aumento da produtividade e diminuição do Lead time de uma Indústria Metalúrgica. Revista Gestão Industrial, 13(1).

Machado, C. M. L. (2014). Ferramenta computacional para apoio à minimização dos desperdícios do processo produtivo.

Machado, C. M., Scavarda, A., Vaccaro, G., Kipper, L. M., \& Khan, M. S. (2015). Healthcare lean operations: Building an effective management framework. organization, 1, 4.

Marafon de Paoli, F., Cezar, W., \& da Silva Santos, J. C. (2016). Implantação da manufatura enxuta e a cultura organizacional: estudo de múltiplos casos. Exacta, 14(1).

Modarress, B., Ansari*, A., \& Lockwood, D. L. (2005). Kaizen costing for lean manufacturing: a case study. International Journal of Production Research, 43(9), 1751-1760.

Paredes, F. J. G., \& Godinho Filho, M. (2017). Lean e QRM: diferentes ou semelhantes? Revisão da literatura. Exacta, 15(1), 137-153.

Pinto, R. A. Q., Tortato, U., Da Veiga, C. P., \& Catapan, A. (2013). Gestão de estoque e lean manufacturing: estudo de caso em uma empresa metalúrgica. Revista Administração em Diálogo$R A D, 15(1)$.

Rother, M., \& Shook, J. (2003). Aprendendo a enxergar. São Paulo: Lean Institute Brasil. 
Saurin, T. A., Ribeiro, J. L. D., \& Marodin, G. A. (2010). Identificação de oportunidades de pesquisa a partir de um levantamento da implantação da produção enxuta em empresas do Brasil e do exterior. Gestão e produção. São Carlos, SP. Vol. 17, n. 4 (out./dez. 2010), p. 829-841.

Shingo, S. (1996). O sistema Toyota de produção. Bookman Editora.

Swenseth, S. R., \& Olson, D. L. (2016). Trade-offs in lean vs. outsourced supply chains. International Journal of Production Research, 54(13), 4065-4080.

Tayyab, M., \& Sarkar, B. (2016). Optimal batch quantity in a cleaner multi-stage lean production system with random defective rate. Journal of cleaner production, 139, 922-934.

Tortorella, G. L., Miorando, R., \& Marodin, G. (2017). Lean supply chain management: Empirical research on practices, contexts and performance. International Journal of Production Economics, 193, 98-112.

Venkataraman, K., Ramnath, B. V., Kumar, V. M., \& Elanchezhian, C. (2014). Application of value stream mapping for reduction of cycle time in a machining process. Procedia Materials Science, 6 , $1187-1196$

Vinodh, S., \& Joy, D. (2012). Structural equation modelling of lean manufacturing practices. International Journal of Production Research, 50(6), 1598-1607.

Wu, P., \& Low, S. P. (2014). Barriers to achieving green precast concrete stock management-a survey of current stock management practices in Singapore. International Journal of Construction Management, 14(2), 78-89.

Yin, R. K. (2015). Estudo de Caso-: Planejamento e Métodos. Bookman editora.

Zylstra, K. D. (2008). Distribuição Lean: a abordagem enxuta aplicada à distribuição, logística e cadeia de suprimentos. Bookman editora. 

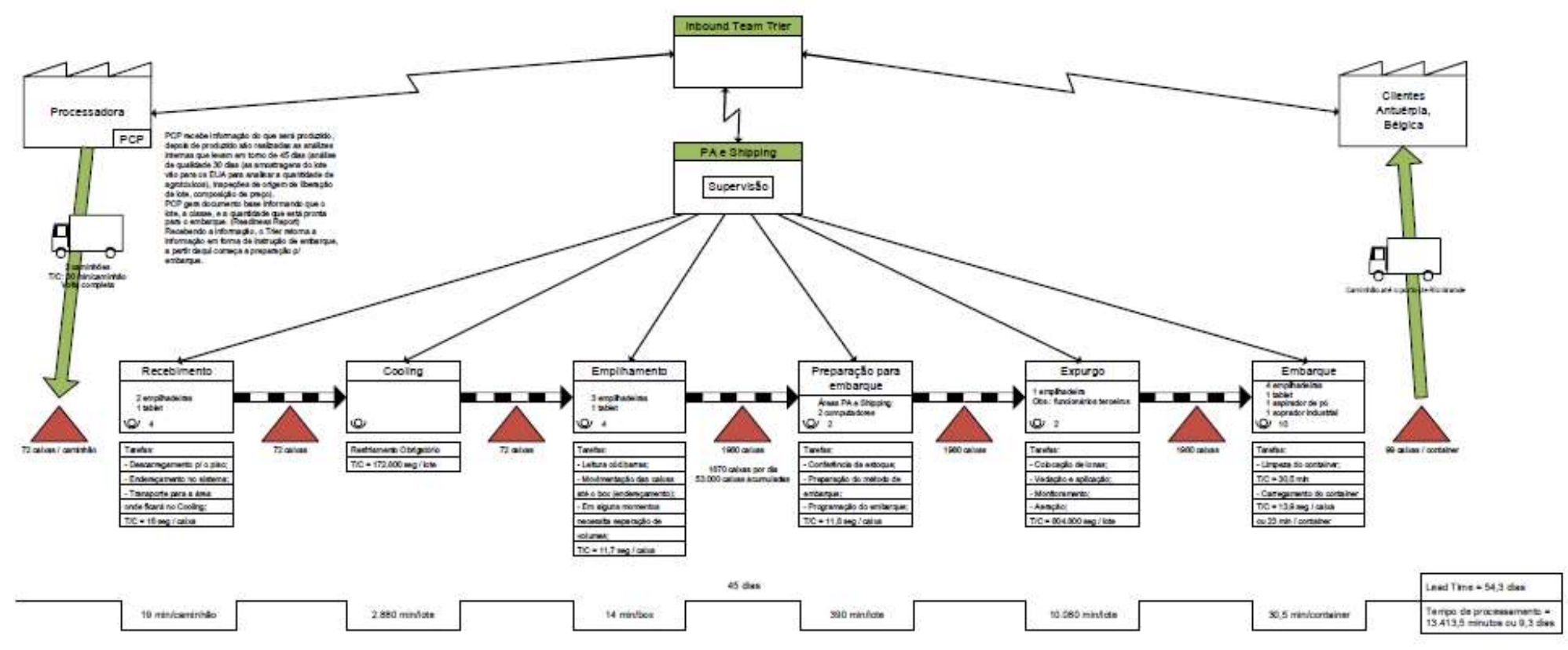

- sm
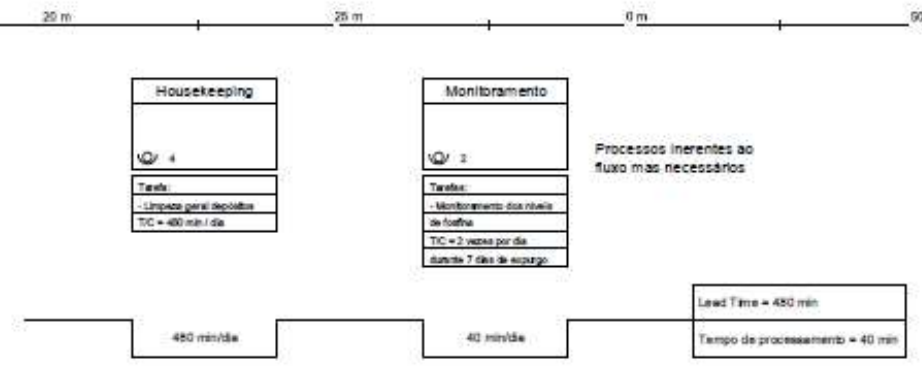
Apêndice B - Mapa de Fluxo de Valor com Proposta de Melhorias

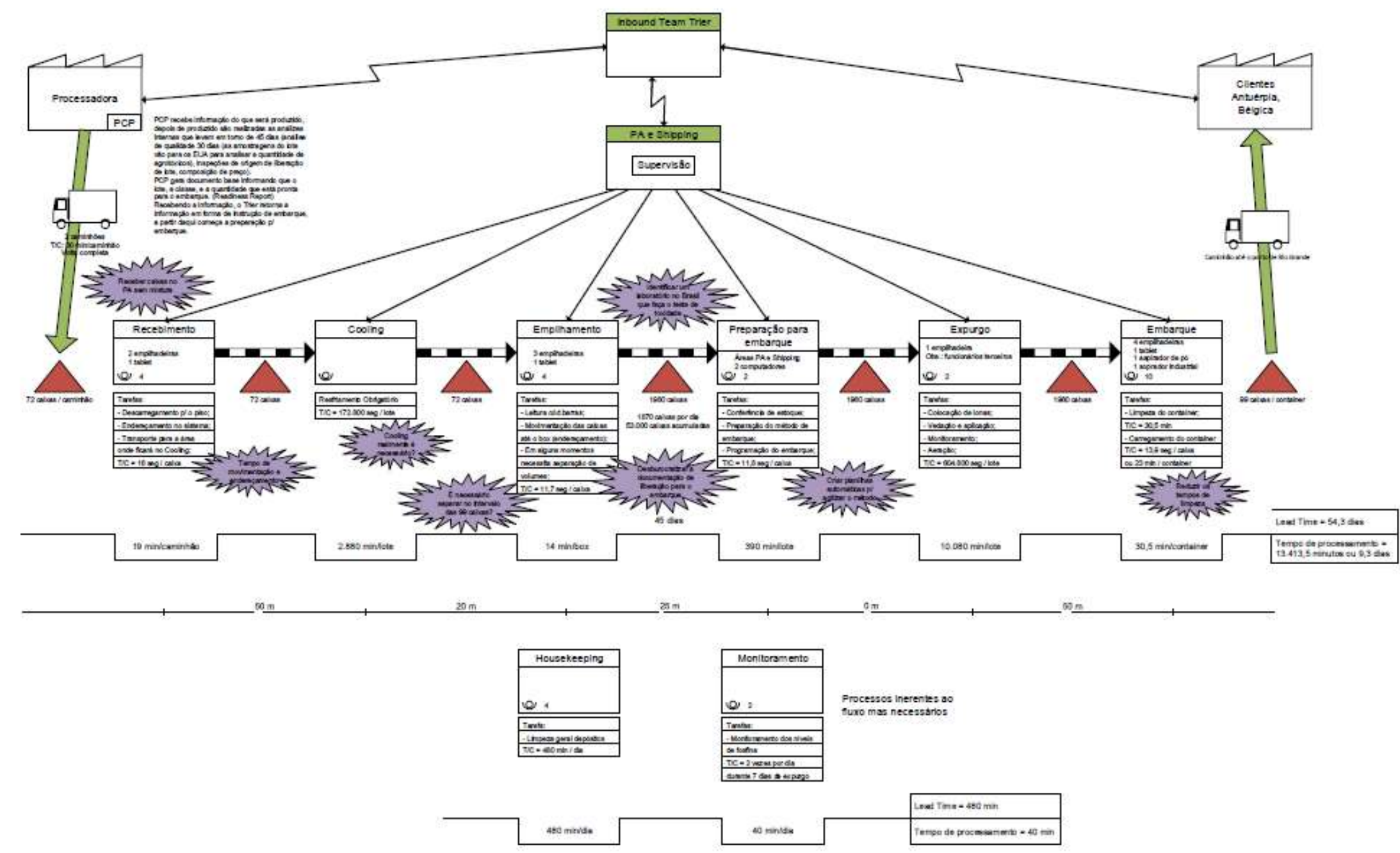


Apêndice C - Mapa de Fluxo de Valor Futuro
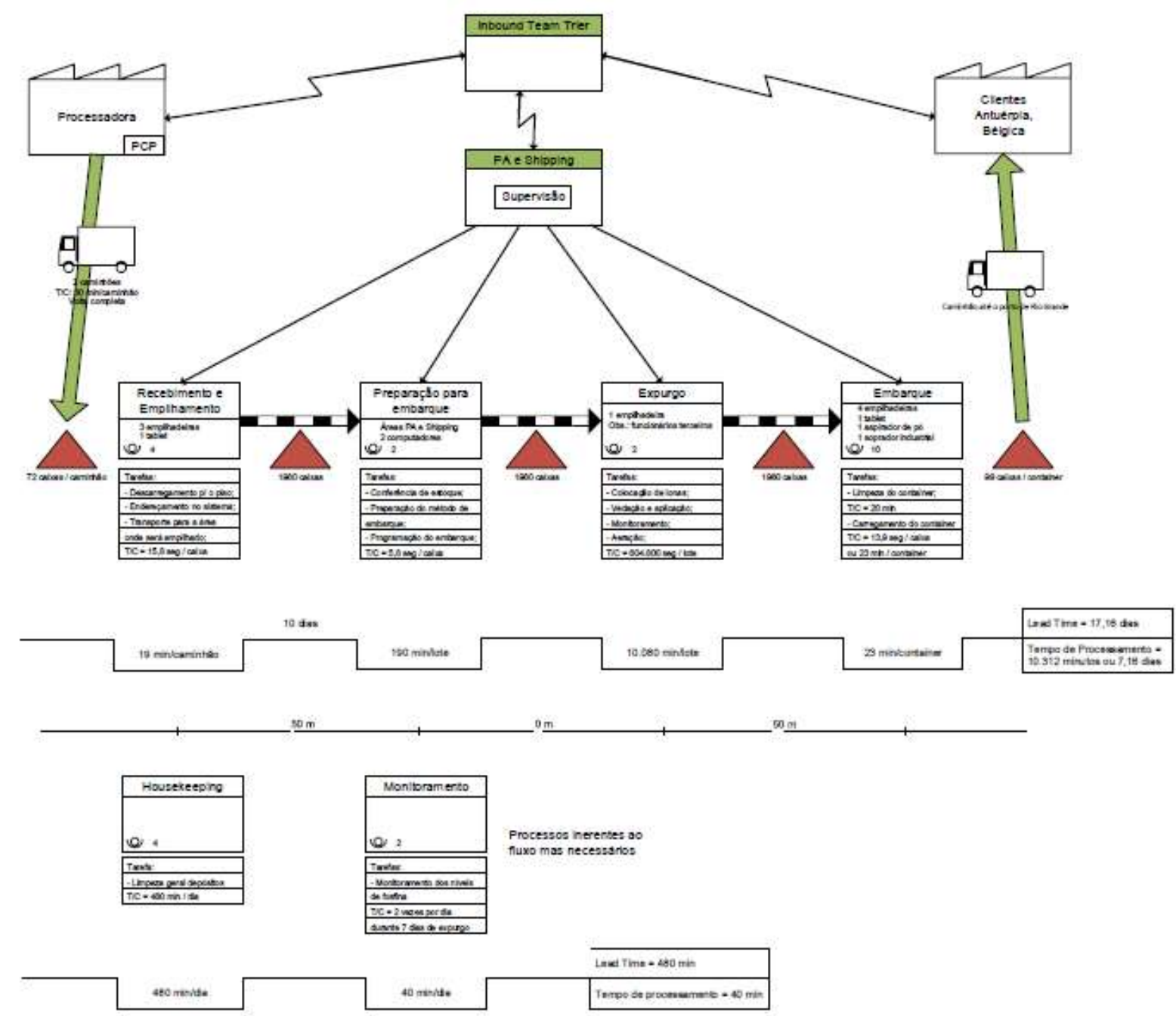
Recebido em: 27 abr. 2018 / Aprovado em: 26 set. 2018

\section{Para referenciar este texto}

Sehnem, E. H., Kipper, L. M., Silva, J. I. da, Freitas, F. de. \&, Choaire, G. T. (2020). Utilização dos princípios da manufatura enxuta e ferramenta de mapeamento de fluxo de valor para a identificação de desperdícios no estoque de produto acabado. Exacta, 18(1), 165-184. https://doi.org/10.5585/Exacta.v18n1.8629. 